\title{
A DQ Synchronous Reference Frame Current Control for Grid Connected Photovoltaic Systems using Single Phase Cascaded H Bridge Multilevel Inverter
}

\author{
V. S. Kirthika Devi, S. G. Srivani
}

\begin{abstract}
This paper projects a high performance decoupled current control using a dq synchronous reference frame for single-phase inverter. For the three-phase inverter the conversion from $A C$ to $D C$ with Proportional Integral controller grants to obtain steady state error for AC Voltages and currents but has a few challenges with the single-phase systems. Hence, an orthogonal pair ( $\beta)$ is created by shifting the phase by one quarter cycle with respect to the real component $(\alpha)$ which is needed for the transformation from stationary to rotating frame. The synchronous reference frame control theory helps in controlling the AC voltage by using $D C$ signal as the reference with the proportional integrator controllers. The implementation of the control is done with two-stage converter with LCL filter for a single-phase photovoltaic system. A modified MPPT Incremental conductance algorithm along with decoupled current control helps in regulating the active and reactive power infused into the grid where the power factor is improved, the efficiency of the system is increased above $95 \%$ and total harmonic distortion for current is also reduced to3\%. The results have been validated using MATLAB.
\end{abstract}

Keywords- Photovoltaic(PV), boost converter, Maximum Power Point Tracking (MPPT), Maximum Power Point (MPP), Incremental conductance (IC), dq Synchronous Reference Frame (SRF), Phase Shifted Pulse Width Modulation (PSPWM), Phase locked loop (PLL), Total Harmonic Distortion (THD).

\section{I.INTRODUCTION}

Presently, worldwide infrastructure of electrical system is going through a major change, due to increase in the electrical energy demand, politics in energy systems, issues due to environmental conditions and an accelerated technological improvement, exclusively in power electronics sectors [1].Rising count of renewable sources is the key to forthcoming worldwide viability. Increasing in number of distributed generators and renewable sources needed new technologies for the development of the grid in order to improvise the reliability of the power supply and power quality [2].The power electronics strategy performs an extensive aspect in combination of renewable sources to grid and in distribution generation[3].

\section{Revised Manuscript Received on December 30, 2019.}

* Correspondence Author

V. S. Kirthika Devi*, VTU Research scholar, Department of Electrical and Electronics Engineering, Amrita School of Engineering, Bengaluru,Amrita Vishwa Vidyapeetham, India. Email: kirthika.rajesh15@gmail.com

S. G. Srivani, Department of Electrical and ElectronicsEngineering, RV College of Engineering Bengaluru, India. Email: srivani.sg@gmail.com

(C) The Authors. Published by Blue Eyes Intelligence Engineering and Sciences Publication (BEIESP). This is an open access article under the CC BY-NC-ND license (http://creativecommons.org/licenses/by-nc-nd/4.0/)
For integrating utility grid along with the renewable resources, converters using two-stages are adopted. The first stage is DC-DC converter system for photovoltaics. Usually, this stage operates withMPPT and the input voltage gets boosted to an applicable level for the next stage. There are several maximum power point algorithm techniques [46].Among several types of MPPT perturb and observe algorithm and IC methods are more regularly used[7]. P\&O logic is often used because of its simplicity;one drawback it has is severaloscillationsaround the maximum power point So IC algorithm is superior exclusively in fast changing environmental circumstances. IC algorithm can precisely track the maximum power point, with fewer oscillations and quicker response thus efficiency of the tracking is improved [8-10].In extension, many alterations to variable step size is incorporated in the IC algorithm to achieve greater efficiency towards the MPP [11-13]. Step up converters are used to obtain regulated voltage output from an unregulated dc voltage input [14-16]. Where the input source can be taken from renewable resources such as PVsystem. The primary function of the later stage is an inverter for most of the systems is to assure that the maximum power obtained has to be injected into the grid smoothly and stably with quality power.

Multilevel inverter topology is one of the main attractive systems because of their extension of voltage to a higher value and for greater power.CHBMLI is more suitable where dc voltage sources are available separately and suitable for applications like photovoltaic, batteries and fuel cells[17-19].To enrich the contents of harmonics of singlephase inverter using multilevel topologies, a fewer modulation techniques are discussed as in [20-23].PLL for synchronizing with grid for a current control strategy is a very big endeavour. Several types of PLL is explained as in [24].The closed loop control strategy using dq synchronous frame for three phase system is well matured in research section[25\&26]. Using single-phasesystem, it is a challenging task to generate error at zero steady state.Hence, single-phase inverter current generates an orthogonal pair[27\&28].As synchronous reference, frame regulators operate on dc quantities it has better improvement than stationary reference frame regulators so that it removes steady state error and generatesbetter transient responseand has the potential of transmitting active and reactive power[29].A filter is required between grid and the inverter to smoothen the waveform.

Published By: 
LCL filter is treated as a better choice whencompared with respect to $\mathrm{L}$ and $\mathrm{LC}$ filter due to its design compactnessand cost effective [30-32]. The transformer less inverter, for the grid connected system provide the better cost welfare ratio and also reaches the better efficiency [3335].

In this paper, the interfacing between the PV system and grid is shown along with two stage converter. The first stage is boost converter. Pulse for boost converter switch is generated using modified IC algorithm, with this algorithm the steady state response is very fast. The second stage is the inverter where a closed loop using dqSRFcontrol strategy forsingle-phase system with filter is adopted for grid photovoltaic system. It is implemented using a PI controller. The pulses for the inverter switches are given using the modified PSPWM method. The simulation is verified using MATLAB tool. Efficiency of proposed work in simulation is about $97 \%$ and THD is $3 \%$ for grid current, which satisfies the IEEE standard grid current value.

\section{SCHEMATIC REPRESENTATION OF THE PROPOSED SYSTEM}

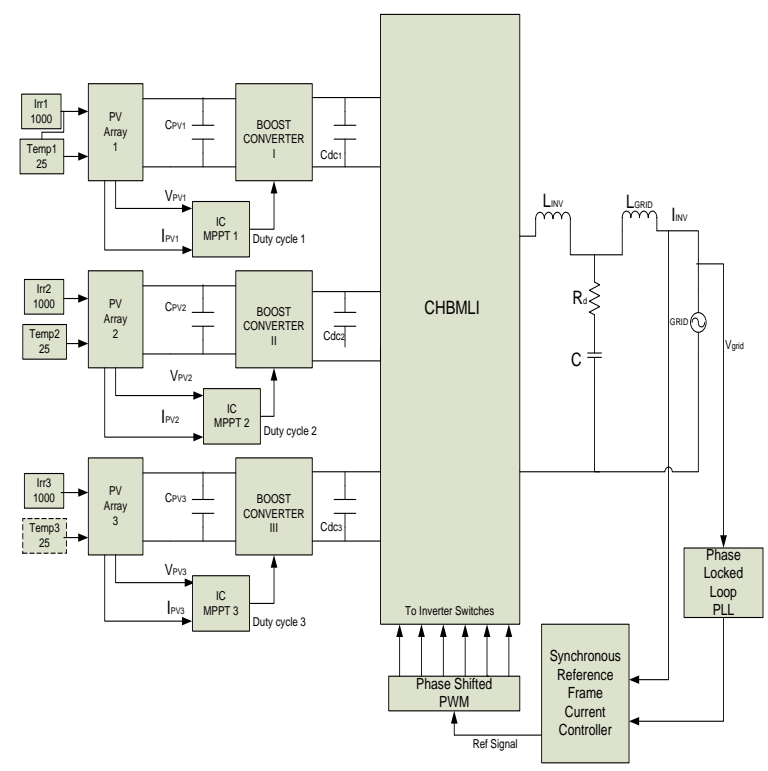

Fig. 1. Block diagram ofsingle-phase SRF current control using CHBMLI

Proposed systems consist of dual stages, for renewable sources integration with grid-connected system. This system has four control strategies. The first control method isIC algorithm, a modified algorithm is adopted in this paper in order to track MPPand to generate pulse for first stage dc-dc boost converter switch. Secondly modified PSPWM [23] is adoptedto generate pulses forinverter. Thirdly LCL filter is to reduce the THD. Finally, current taken from filter output and grid voltageis given to dq SRF current controller method through PLL to develop sine wave, a reference signal and pulses are created by comparing with carrier signals for CHBMLI switches. PLL is mainly used to control frequency and to synchronise the phase for the proposed system with grid. The block diagram is shown in Fig1.

\section{Control Techniques for the suggested system}

Proposed model is detailed with two-stage inverter. Input source is taken from solar and its maximum power is tracked using modified variable IC algorithm. The pulses generated by this areapplied to first stage ofboost converter switch. Second stage is CHBML, output of this inverter is connected to LCL filter for reducing harmonic contents. A closed loop current control using d-q SRF is adopted and a sine reference wave is generated which is then compared with carrier waves of PSPWM and the developed pulses are given to the inverter switches.

\section{A. Modified IC algorithm}

The algorithm is developed using variable step size IC method. Proposed algorithm depends only on the transformation in the power of $\mathrm{PV}$. Where $\Delta \mathrm{P} / \Delta \mathrm{V}=0$ reaches at the MPP as in expressions in conventional model. Proposed flowchart is illustrated in Fig.2.In modified algorithm $\Delta \mathrm{d}_{\max }$ with some constant value is fixed based on the duty cycle. If $\Delta \mathrm{d}$ is higher than that of the $\Delta \mathrm{d}_{\max }$ then $\Delta \mathrm{d}$ should be equaling to $\Delta \mathrm{d}_{\max }$ else $\Delta \mathrm{d}=\Delta \mathrm{d}+\Delta \mathrm{d}_{\max }$ then the algorithm follows with $\Delta \mathrm{V}=0$ as in conventional IC.Direct control logic is used,henceno PI is needed to sustain MPP, whichdepends only with respect to power change as in [13]. $\Delta d=N|\Delta P|$

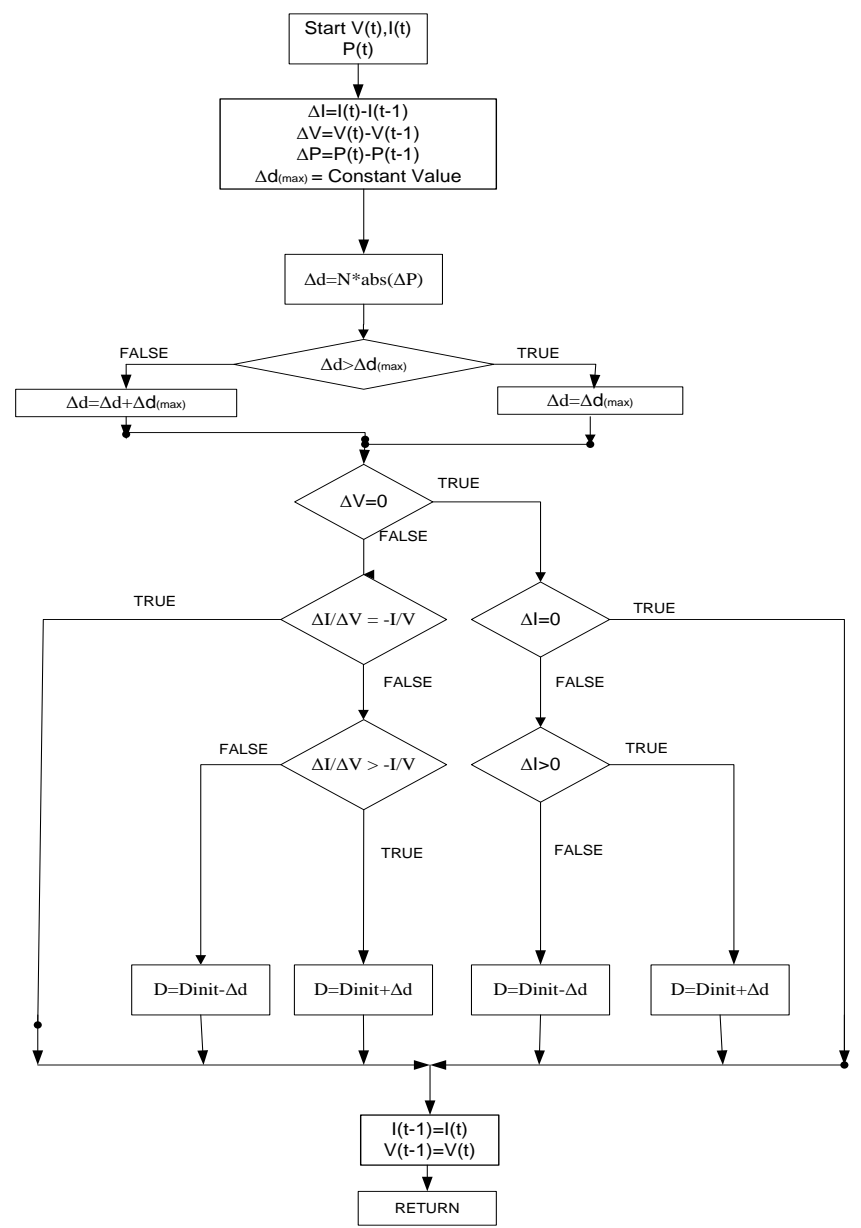

Fig. 2. Flowchart for Modified IC algorithm 
$N$ states the scaling factor, which maintains the step-size to accord at intervals of the tracking certainty and its convergence speed. Excluding the denominator by $\Delta \mathrm{V}$ in the proposed technique makes the algorithm simpler and also tracks the maximum power and gives improved efficiency. Parameter values for PV panel used is detailed in Table I

Table-I: Parameters of Simulated PV module

\begin{tabular}{|c|c|}
\hline Components & $\begin{array}{c}\text { Values for PV } \\
\text { Model }\end{array}$ \\
\hline Current at Short Circuit $\left(\mathrm{I}_{\mathrm{sc}}\right)$ & $\mathbf{8 . 7} \mathrm{A}$ \\
\hline Current at the Maximum $\left(\mathrm{I}_{\mathrm{mpp}}\right)$ & $\mathbf{8 . 2} \mathrm{A}$ \\
\hline Maximum Power $\left(\mathrm{P}_{\max }\right)$ & $\mathbf{1 5 0 . 8 8} \mathrm{W}$ \\
\hline Series Cells & $\mathbf{6 0}$ \\
\hline Voltage at the Maximum $\left(\mathrm{V}_{\mathrm{mpp}}\right)$ & $\mathbf{1 8 . 4} \mathrm{A}$ \\
\hline Voltage at Open Circuit $\left(\mathrm{V}_{\text {oc }}\right)$ & $22.8 \mathrm{~V}$ \\
\hline
\end{tabular}

(a) Designing of $P V d c$ link:

This acts as a load-balancing device. This helps by securing the inverter circuit from temporary electromagnetic interference, voltage spikes and surges. DC link capacitor is an important necessary element to accomplish the improved performance of the system. DC link is calculated using the expression (2).

$C_{P V}=\frac{V_{p v} * D}{4 * L_{d c} * \Delta V_{p v} * f_{d c}^{2}}$

Where, $\mathrm{V}_{\mathrm{pv}}$ is the PV voltage used in this system. D, duty cycle of boost converter. $\mathrm{L}_{\mathrm{dc}}$ is converterinductor value. $\Delta V_{\mathrm{pv}}$ is $2 \%$ of the PV voltage. $\mathrm{f}_{\mathrm{dc}}$ is converter frequency.

\section{B.Designing of step up converter}

In this paper dc-dc boost converter is utilized and the gating pulse for the switch is generated from IC algorithm where the maximum power is tracked. Step up converter is illustrated in Fig.3.

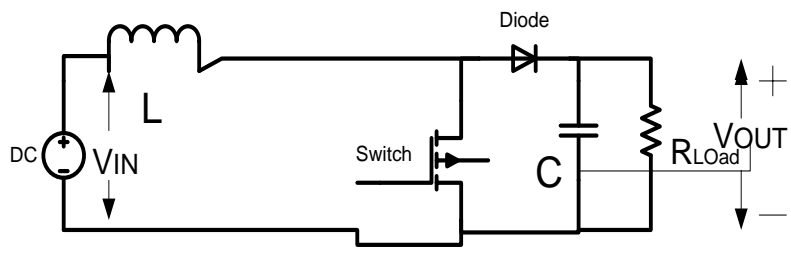

Fig. 3. Circuit diagram of step up Converter

Duty cycle (D) is calculated as shown in the below expression[14-16]

$\frac{V_{\text {OUT }}}{V_{I N}}=\frac{1}{1-D}$

The boost converter inductor value is calculated using the expression (4)

$L=\frac{\left(V_{I N}\right) * D}{\left(\Delta i_{L}\right) * f}$

The capacitance value is calculated by
$C=\frac{\left(V_{\text {OUT }}\right) * D}{\left(\Delta V_{\text {OUT }}\right) * f * R_{\text {Load }}}$

$\mathrm{R}_{\text {Load }}$ is calculated using $\left(\mathrm{V}_{\text {OUT }}\right)^{2} / \mathrm{P}_{\text {IN }}$

Where, the $\mathrm{I}_{\text {IN }}$ is $8.2 \mathrm{~A}, \mathrm{~V}_{\text {IN }}$ is $18.4 \mathrm{~V}, \mathrm{P}_{\mathrm{IN}}$ is 150 . 88W.The Calculated $\mathrm{L}$ is $260 \mu \mathrm{H}, \mathrm{C}$ is $52 \mu \mathrm{F}, \Delta \mathrm{i}_{\mathrm{L}}$ is assumed $40 \%$ and $\Delta \mathrm{V}_{\text {OUT }}$ is assumed $1 \%$. The $\mathrm{R}_{\text {Load }}$ is $80.2 \Omega$.

(a) Designing of inverter dc link:

Capacitor in between converter and inverter is determined using expression (6).

$C_{d c}=\frac{P_{\text {MAX }}}{2 * \omega_{\text {grid }} * v_{\text {ripple }} * V_{d c} *}$

here, $P_{\text {MAX }}$ is output maximum power of boost converter for each $\mathrm{PV}, f_{\mathrm{s}}$ is the switching frequency, $v_{\text {ripple }}$ represents the amplitude of MPP voltage and it is considered to be less than $6 \%$ of the voltage MPP and for the proposed system it is considered as $2.5 \%$. $V_{\mathrm{dc}}$ is voltage output of boost converter, and ' $\omega_{\text {grid }}$ ' is grid frequency.The calculated $C_{d c}$ value is $4748 \mu \mathrm{F}$.

\section{C.Multilevel Inverter (CHBMLI)}

In medium and high power applications, Cascaded $\mathrm{H}$ Bridge (CHBMLI) multilevel inverter plays a vital role. This resides number of series $H$ Bridges, each $h$ bridge is connected with separate DC source. Renewable resources such as solar, fuel cells,battery can be replaced instead of each Dc source. Seven levelsis incorporated in this paper. The levels are calculated with expression $2 \mathrm{~N}+1$.Here $\mathrm{N}$ denotes the number of levels. This arises with seven different output voltages such as $+3 \mathrm{~V}_{\mathrm{dc}},+2 \mathrm{~V}_{\mathrm{dc}},+1 \mathrm{~V}_{\mathrm{dc}}, 0$,$1 \mathrm{~V}_{\mathrm{dc}},-2 \mathrm{~V}_{\mathrm{dc}}$, and $-3 \mathrm{~V}_{\mathrm{dc}}$. CHBMLI seven level is illustrated in Fig.4.PV source is used as a input DC source.The switching pattern is shown in Table II.

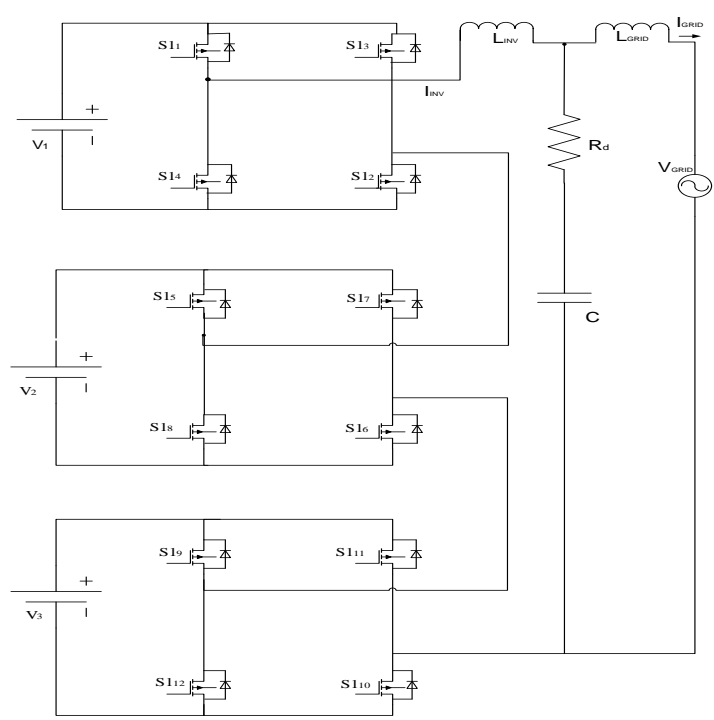

Fig. 4. Circuit Diagram of CHBMLI with grid 
Table-II:Pattern for Seven Leven CHBMLI Switching

\begin{tabular}{|c|c|c|c|c|c|c|c|c|c|c|c|c|}
\hline \multirow{4}{*}{$\begin{array}{l}\mathbf{V} \\
\text { DC }\end{array}$} & \multicolumn{12}{|c|}{ CHBMLI switching pattern } \\
\hline & S & S & $\mathrm{S}$ & S & S & S & S & S & S & S & S & $\mathrm{S}$ \\
\hline & 1 & 1 & 1 & 1 & 1 & 1 & 1 & 1 & 1 & 1 & 1 & 1 \\
\hline & 1 & 2 & 3 & 4 & 5 & 6 & 7 & 8 & 9 & 10 & 11 & 12 \\
\hline+3 & 1 & 1 & 0 & 0 & 1 & 1 & 0 & 0 & 1 & 1 & 0 & 0 \\
\hline+2 & 1 & 1 & 0 & 0 & 1 & 1 & 0 & 0 & 0 & 1 & 0 & 1 \\
\hline+1 & 1 & 1 & 0 & 0 & 0 & 1 & 0 & 1 & 0 & 1 & 0 & 1 \\
\hline \multirow{2}{*}{0} & 0 & 1 & 0 & 1 & 0 & 1 & 0 & 1 & 0 & 1 & 0 & 1 \\
\hline & 1 & 0 & 1 & 0 & 1 & 0 & 1 & 0 & 1 & 0 & 1 & 0 \\
\hline-1 & 0 & 0 & 1 & 1 & 1 & 0 & 1 & 0 & 1 & 0 & 1 & 0 \\
\hline-2 & 0 & 0 & 1 & 1 & 0 & 0 & 1 & 1 & 1 & 0 & 1 & 0 \\
\hline-3 & 0 & 0 & 1 & 1 & 0 & 0 & 1 & 1 & 0 & 0 & 1 & 1 \\
\hline
\end{tabular}

(a)Designing of synchronous reference frame current controller for cascaded $h$ bridge inverter:

The inverter $\mathrm{I}_{\text {inv }}$ current should be in phase with grid $\mathrm{V}_{\text {grid }}$ to send the actual power to the grid system. Hence dqSRF controller approach is adopted.Orthogonal signal pair for

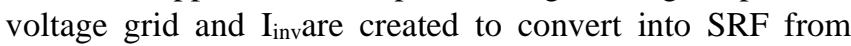
stationary reference frame, since the adopted controller is utilised for a single phase system. For single-phase, it is a very challenging issue to achieve zero steady state error at grid frequency. Hence, SRF control helps in creating two phases by generating an orthogonal pair, which is shown in Fig.5. The PLL is utilised to trail the grid phase angle Voltage.

The inverter $\mathrm{I}_{\alpha}$ current is used to generate its pair $\mathrm{I}_{\beta}$. The grid $\mathrm{V}_{\mathrm{g} \alpha}$ voltage is used to generate its pair $\mathrm{V}_{\mathrm{g} \beta}$. [36]

$$
V_{g \alpha}(t)=V \cos (\omega t)
$$

$$
V_{g \beta}(t)=V \sin (\omega t)
$$

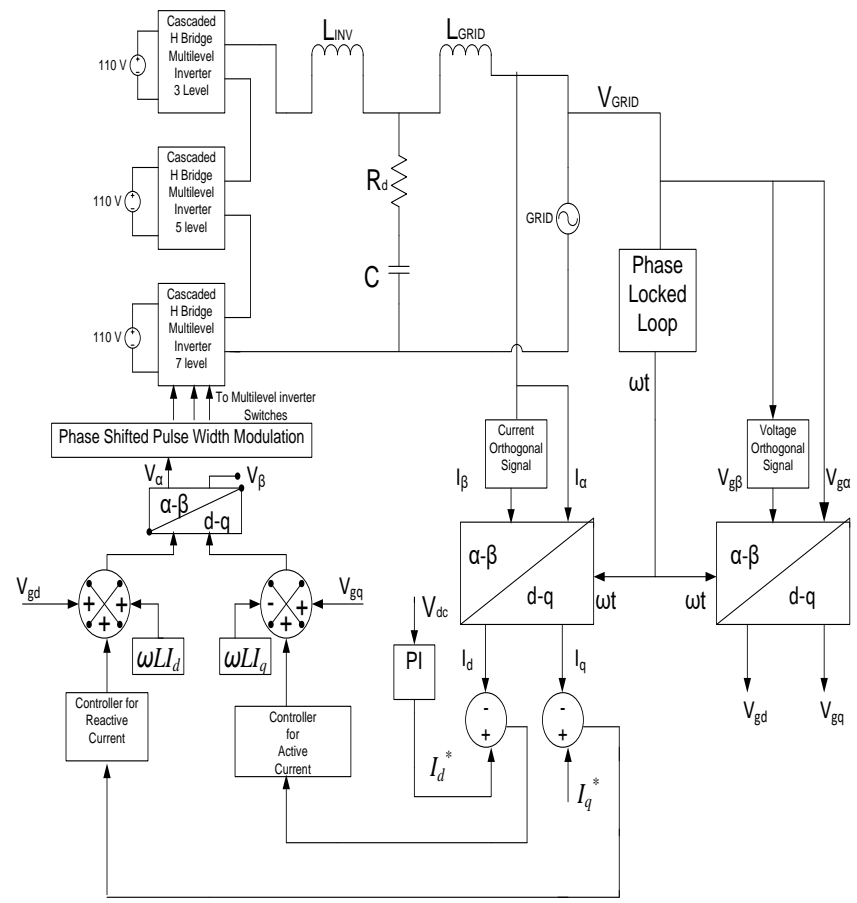

Fig. 5. Closed loop current controller using SRF method

$$
\begin{aligned}
& I_{\alpha}(t)=I \cos (\omega t+\phi) \\
& I_{\beta}(t)=I \sin (\omega t+\phi)
\end{aligned}
$$

Where $\mathrm{V}$ is amplitude voltage accessed from grid and phase angle $\omega t$ is generated using PLL. The inverter $I_{\alpha}(t)$ current and its pair $I_{\beta}(t)$ is given in the expression (9) and (10). $\Phi$ is the phase angle of the current flowing in inverter.

$I_{d}$ and $I_{q}$ are constant DC component with the help of the conversion from stationary rotating frame to synchronous rotating frame and this control action assassinated with the help of the PI controller [36]

$$
\left[\begin{array}{l}
I_{d} \\
I_{q}
\end{array}\right]=\left[\begin{array}{cc}
\cos \theta & \sin \theta \\
-\sin \theta & \cos \theta
\end{array}\right]\left[\begin{array}{c}
I_{\alpha} \\
I_{\beta}
\end{array}\right]
$$

By using expressions (9),(10) in expression (11) we get where $\omega \mathrm{t}=\mathrm{\theta}$

$$
\left[\begin{array}{l}
I_{d} \\
I_{q}
\end{array}\right]=\left[\begin{array}{l}
I \cos \phi \\
I \sin \phi
\end{array}\right]
$$

The phase angle $\Phi$ is pretended to be $0(\Phi=0)$ in order to supply actual power. Hence the expression (12) becomes

$\left[\begin{array}{l}I_{d} \\ I_{q}\end{array}\right]=\left[\begin{array}{l}I_{\max } \\ 0\end{array}\right]$

Where $\mathrm{I}_{\max }$ is the maximum current output from inverter. The error signal is developed from expressions (14) and (15)

$e_{d}(t)=I_{d}{ }^{*}-I_{d}(t)$

$e_{q}(t)=I_{q}^{*}-I_{q}(t)$

Where $I_{d}{ }^{*}$ is obtained using dc voltage from boost converter, itis the reference current which develops the True power and supplied to the grid. $I_{q}{ }^{*}$ is the reference current which develops the reactive power and is zero.

Inverter in dq system the continuous time state equation relies upon the inverter model in the SRF controller coupling condition on the inverter side and is given in the expression (16) and (17)

$V_{i d}=V_{g d}+R i_{d}+L \frac{d i_{d}}{d t}-\omega L i_{q}$

$V_{i q}=L \frac{d i_{q}}{d t}+V_{g q}+R i_{q}+\omega L i_{d}$

The $\mathrm{d}$ and $\mathrm{q}$ decoupling condition on the controller side is given in the expression (18) and (19)

$$
\begin{aligned}
& V_{i d}=V_{g d}-\omega L i_{q}+\left[k_{p}+\frac{k_{i}}{s}\right]\left(i_{d}{ }^{*}-i_{d}\right) \\
& V_{i q}=V_{g q}+\omega L i_{d}+\left[k_{p}+\frac{k_{i}}{s}\right]\left(i_{q}^{*}-i_{q}\right) \\
& {\left[\begin{array}{c}
V_{\alpha} \\
V_{\beta}
\end{array}\right]=\left[\begin{array}{ll}
\cos \omega t & -\sin \omega t \\
\sin \omega t & \cos \omega t
\end{array}\right]\left[\begin{array}{c}
V_{i d} \\
V_{i q}
\end{array}\right]}
\end{aligned}
$$

In the above expression the reference signal $V_{\alpha}$ is used for the PSPWM. The tuned value for $k_{p}$ is 4.58 and $k_{i}$ is 0.02 .

\section{(b) Design of modified PSPWM for CHBMLI:}

Modified PSPWM technique in this system is shown in Fig. 6[23]. The carrier wave signals are selected with respect to the expression (n-1)/2, where $n$ is number of levels.

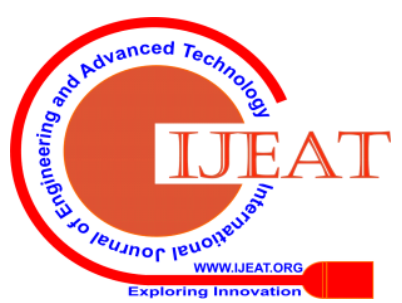


$\theta=\frac{360}{\frac{n-1}{2}}$

$120^{0}$ phase difference is generated between each carrier signals with expression(21).This algorithm is developed similar to an phase opposition disposition (POD)logic for the phase shifting technique.The reference signal which is created with the help of closed loop control is then compared with the carrier signals and the generated pulses are applied to the inverter switches.

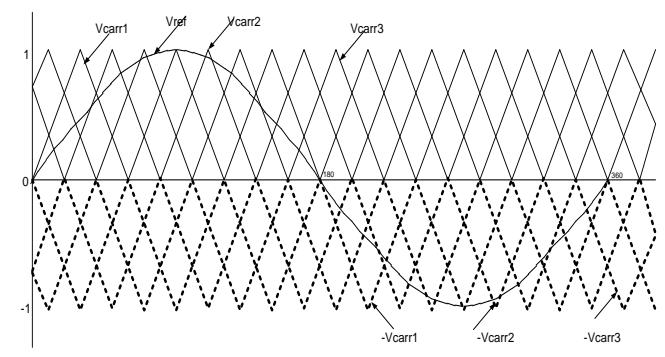

Fig. 6. Modified phase shifted pulse width modulation for cascaded $h$ bridge inverter

(c) Design of filter using LCL method:

The design of the converter side inductance value in to reduce the ripples that has been developed by the voltage source inverter and is calculated using the expression (22). The LCL filter circuit diagram is depicted in Fig.7

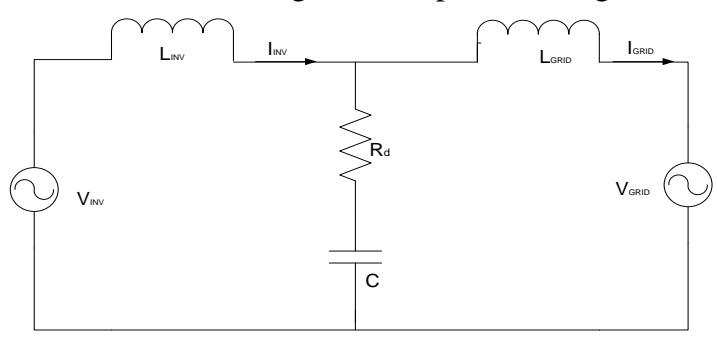

Fig. 7. Filter design circuit using LCL

The inductor placed in the inverter side is estimated using the expression as in [32]

$$
\frac{V_{d c}}{6.4 * f_{S W} * I_{\text {peak }}} \leq L_{I N V} \leq \frac{V_{d c}}{2.4 * f_{S W} * I_{\text {peak }}}
$$

$\mathrm{V}_{\mathrm{dc}}$ is dc voltages given to CHBMLI, $\mathrm{f}_{\mathrm{Sw}}$ is switching frequency, $\mathrm{I}_{\text {peak }}$ is gridcurrent maximum value.The capacitor for filter is estimated using the equation [32]

$$
\begin{aligned}
& C=\frac{0.05 * P_{\text {rated }}}{\omega_{g} * V_{G R I D}^{2}} \\
& f_{\text {res }}=\frac{1}{2 \pi} X \sqrt{\frac{L_{I N V}+L_{G R I D}}{L_{I N V} * L_{G R I D} * C}} \\
& R_{d}=\frac{1}{3 * \omega_{r e s} * C}
\end{aligned}
$$

$\mathrm{P}_{\text {rated }}$ is peak power, $\omega_{\mathrm{g}}$ is angular frequency of grid and $\mathrm{V}_{\text {GRID }}$ is grid voltage root mean square, $\mathrm{f}_{\text {res }}$ is the frequency due to resonance, $R_{d}$ is the resistor due to damping.

The grid side inductor value is calculated using the expression

$$
L_{G R I D}=r^{*} L_{I N V}
$$

The percentage of the factor $r$, between $L_{\text {INV }}$ and $L_{G R I D}$ is used in this model as 0.6 to find the grid Inductance value.The parameter values for the design of the filters are shown in Table III.

Table-III: LCLfilter circuit parameters

\begin{tabular}{|c|c|}
\hline Parameters & Values \\
\hline Inductor at inverter side ( $\left.\mathrm{L}_{\mathrm{INV}}\right)$ & $3.76 \mathbf{~ m H}$ \\
\hline Inductor at grid side $\left(\mathrm{L}_{\mathrm{GRID}}\right)$ & $2.256 \mathrm{mH}$ \\
\hline Capacitor Value for filter $(\mathrm{C})$ & $1.362 \boldsymbol{\mu F}$ \\
\hline Damping Resistor $\left(\mathrm{R}_{\mathrm{d}}\right)$ & $\mathbf{1 0 \Omega}$ \\
\hline Resonance frequency $\left(\mathrm{f}_{\mathrm{res}}\right)$ & $3632 \mathrm{~Hz}$ \\
\hline Fundamental frequency & $50 \mathrm{~Hz}$ \\
\hline Switching frequency & $5 \mathrm{kHz}$ \\
\hline Voltage at DC $\left(\mathrm{V}_{\mathrm{dc}}\right)$ & $330 \mathrm{~V}$ \\
\hline Grid Voltage $\left(\mathrm{V}_{\mathrm{GRID}}\right)$ & $230 \mathrm{~V}$ \\
\hline
\end{tabular}

\section{IV.SIMULATION ANALYSIS RESULTS}

Simulation results of proposed system are analyzed and same is compared with conventional IC algorithm. Proposed and conventional system is even analyzed for different irradiances such as $1000 \mathrm{~W} / \mathrm{m}^{2}, 400 \mathrm{~W} / \mathrm{m}^{2}$ and 700 $\mathrm{W} / \mathrm{m}^{2}$ respectively.For the conventional variable step IC algorithm, the ripple is more when compared to the modified algorithm.

Fig8.illustrates modified variable step size IC algorithm and Fig.9.Shows the conventional Variable step size IC algorithm for $1000 \mathrm{~W} / \mathrm{m}^{2}$ Irradiance level.Fig. 10, and Fig. 11 depicts waveforms for conventional and modified IC for different irradiance levels. Fig. 12 Shows voltage at dc link capacitor and boost voltage are same.

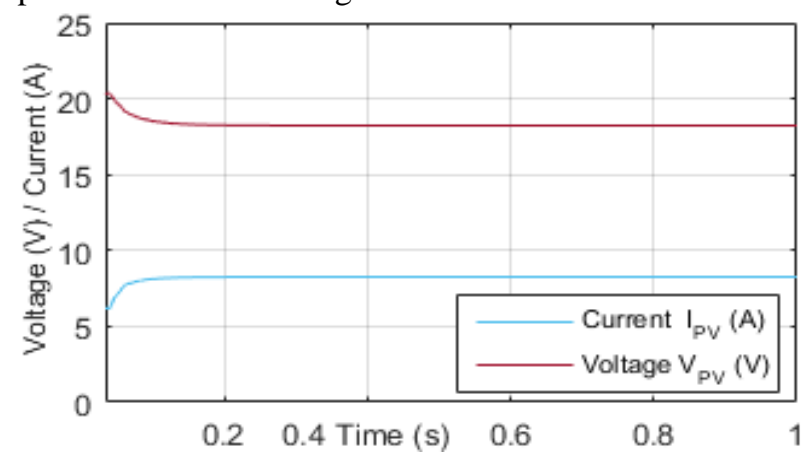

(a)

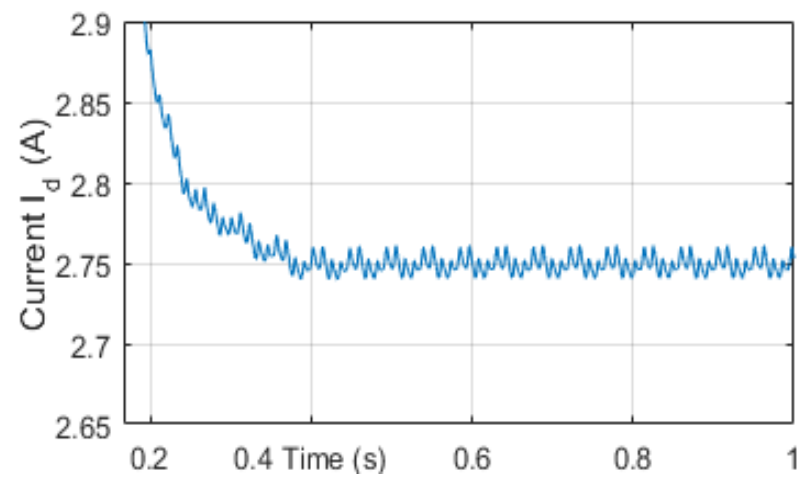

(b) 
A DQ Synchronous Reference Frame Current Control for Grid Connected Photovoltaic Systems using Single Phase Cascaded $\mathrm{H}$ Bridge Multilevel Inverter

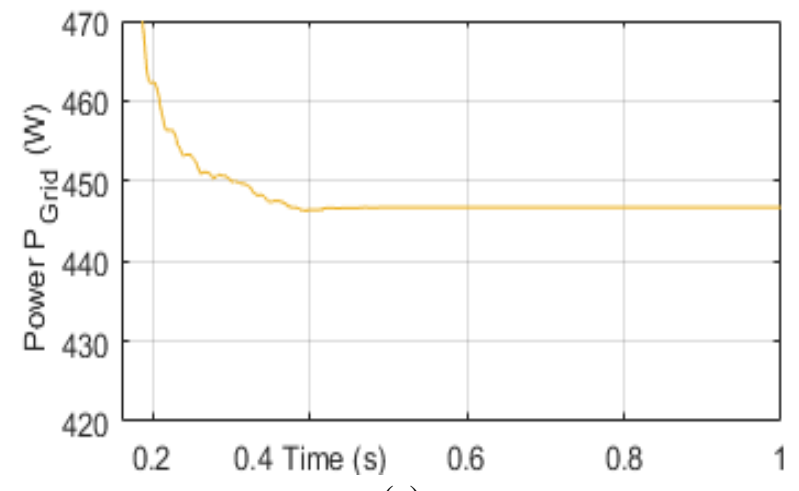

(c)

Fig.8.Modified Variable step size IC Waveforms(a)V and Iof PV output at $1000 \mathrm{~W} / \mathrm{m}^{2}$ (b)Current at the output of the dq Synchronous Ref Frame(c)Output power injected to the Grid

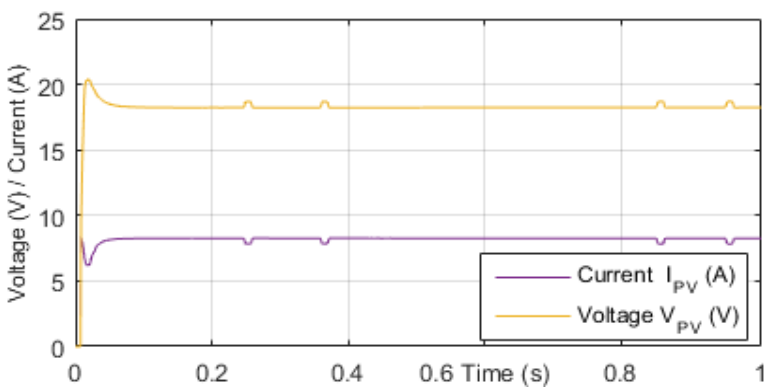

(a)

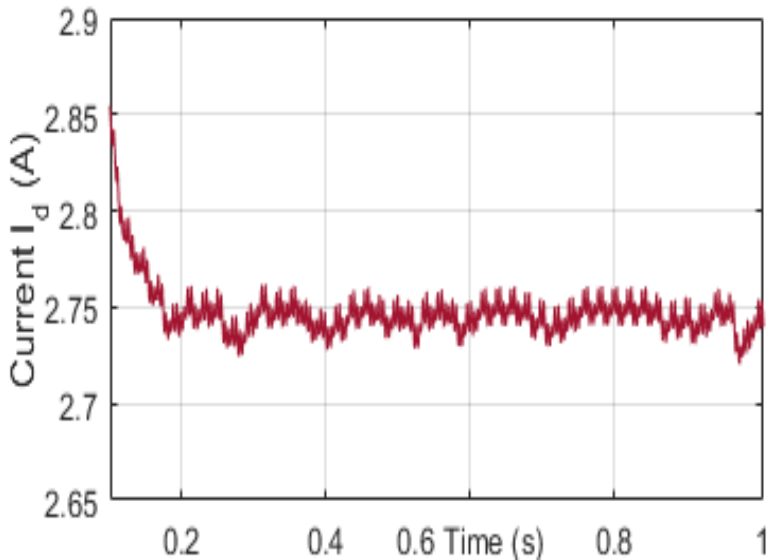

(b)

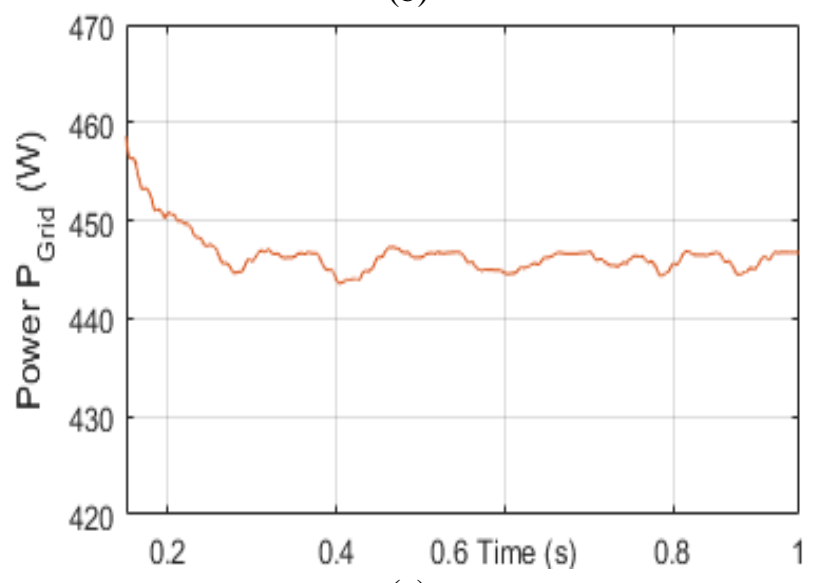

(c)

Fig.9.Conventional Variable Step Size IC Waveforms(a)V and Iof PV output at $1000 \mathrm{~W} / \mathrm{m}^{2}$ (b)Current at the output of the dq Synchronous Ref Frame(c)Output power injected to the Grid

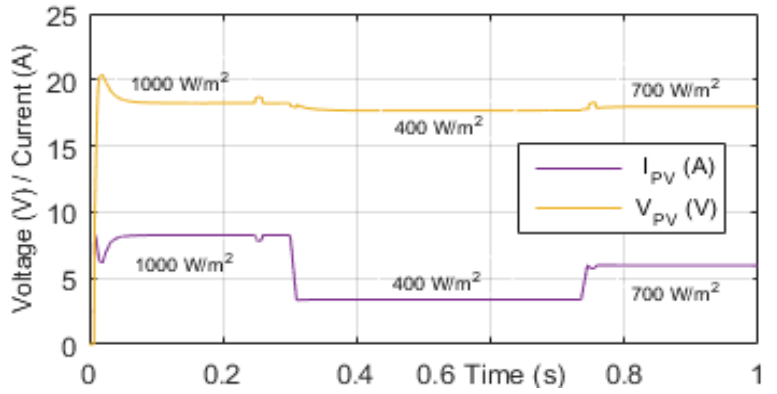

(a)

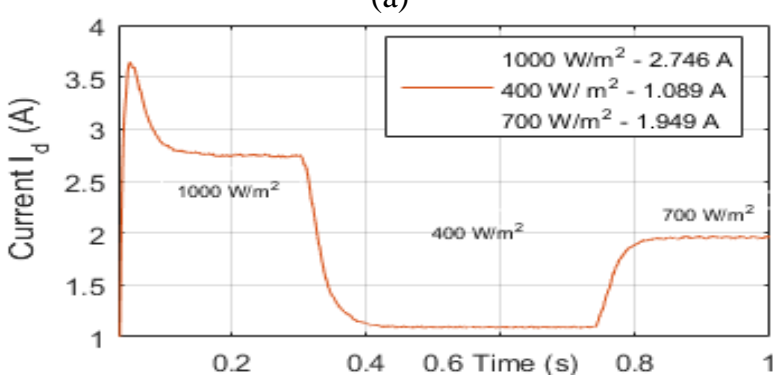

(b)

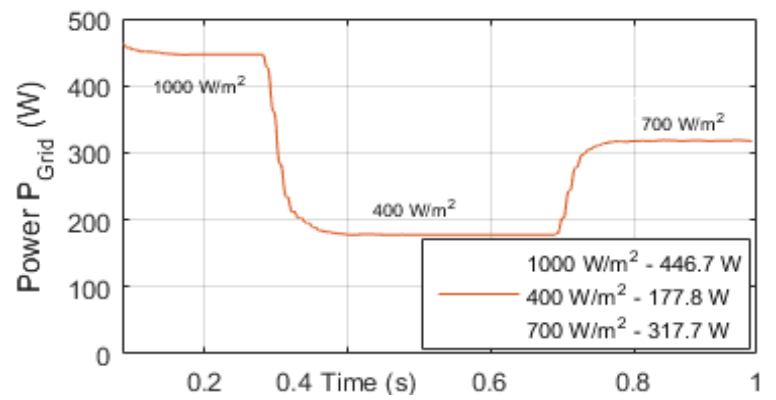

(c)

Fig.10.Modified Variable step size IC Waveformsfor different Irradiance levels $1000 \mathrm{~W} / \mathrm{m}^{2}, 400 \mathrm{~W} / \mathrm{m}^{2}, 700$ $\mathrm{W} / \mathrm{m}^{2}$ (a)Current and Voltage at the output of PV(b)Current at the output of the dq Synchronous Ref Frame(c)Output power injected to the Grid

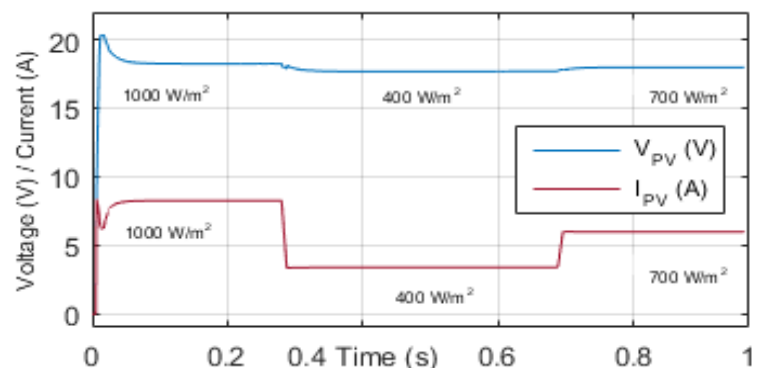

(a)

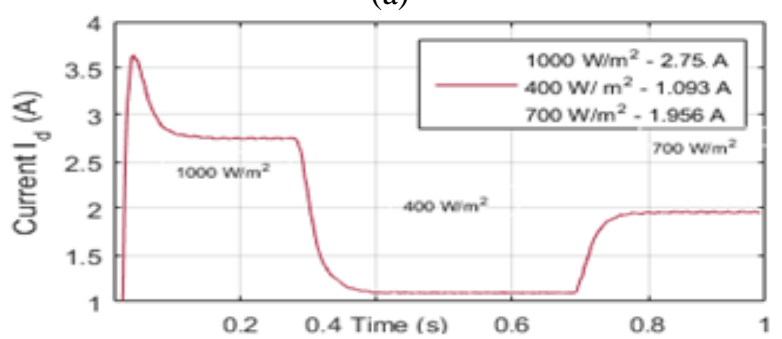

(b) 


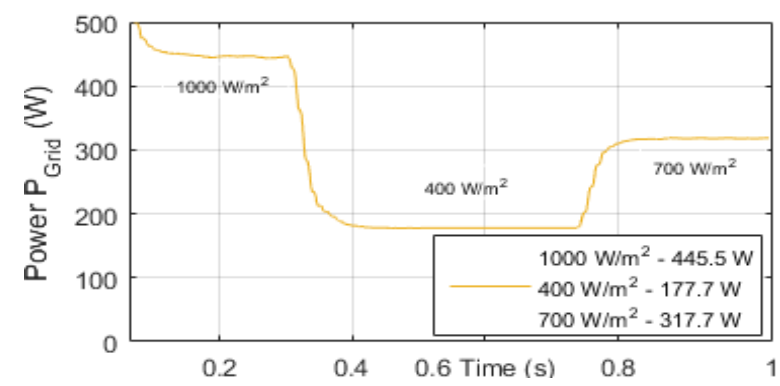

(c)

Fig.11. Conventional Variable step size IC Waveformsfor different Irradiance levels $1000 \mathrm{~W} / \mathrm{m}^{2}, 400 \mathrm{~W} / \mathrm{m}^{2}, 700$

$\mathrm{W} / \mathrm{m}^{2}(\mathrm{a})$ Current and Voltage at the output of PV at(b)Current at the output of the dq Synchronous Ref

Frame(c)Output power injectedto the Grid

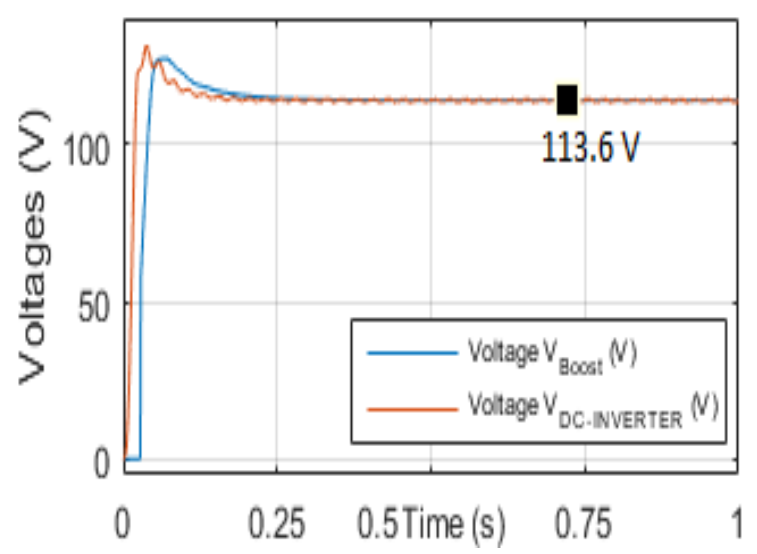

Fig.12.Output voltage of the Dc link and the Boost

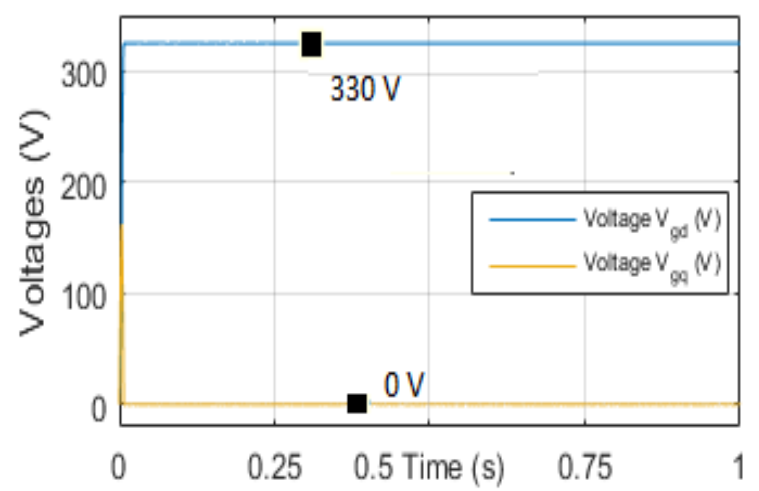

Fig.13.dq Synchronous Ref frame voltage of the grid

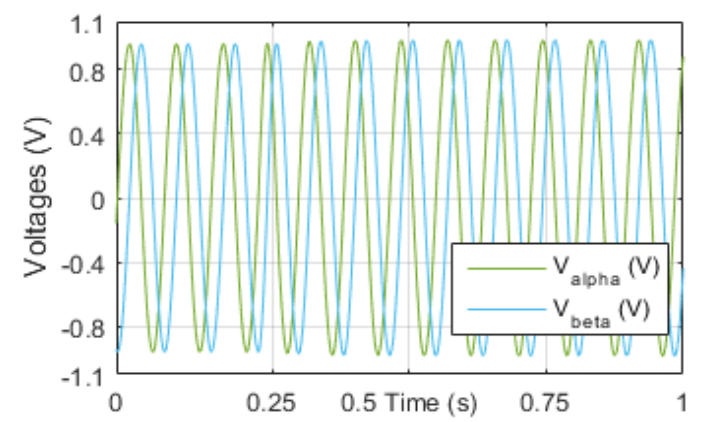

Fig.14. alpha and beta voltages created by the orthogonal pair

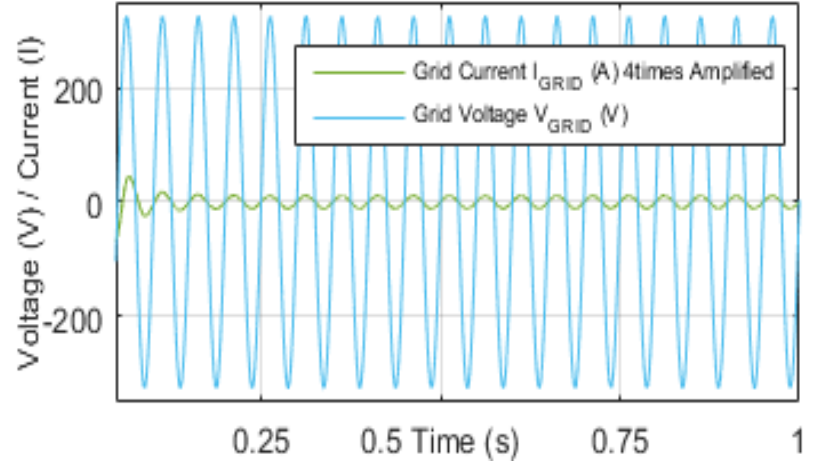

Fig.15. Grid voltage and grid current

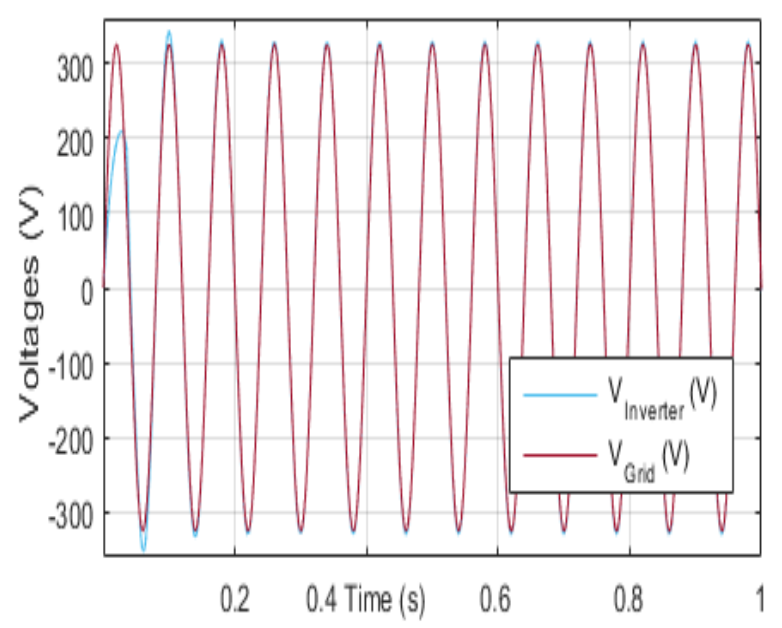

Fig.16. Synchronisation of the inverter and grid voltage

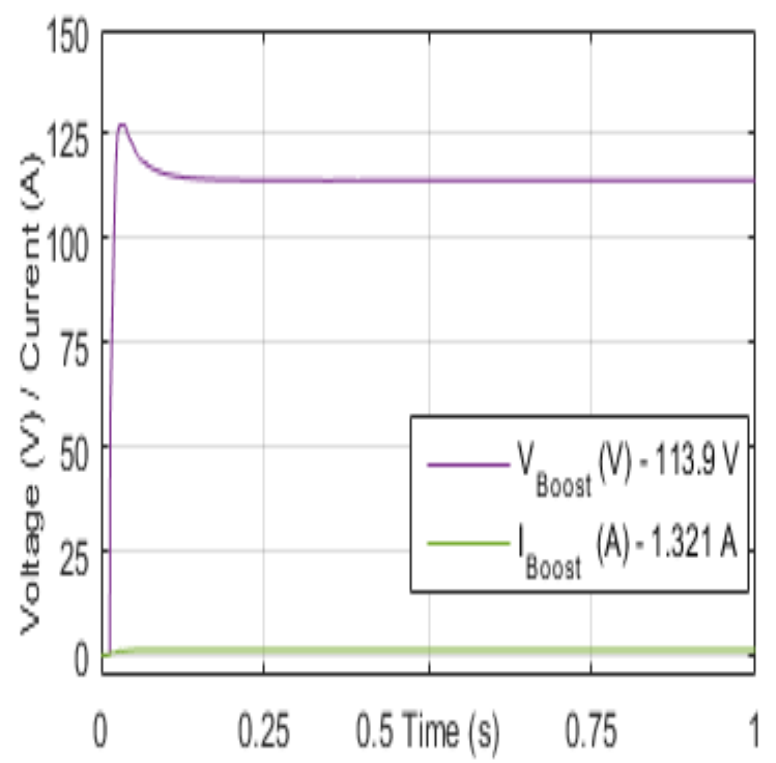

Fig.17. $V$ and $I$ at the output of boost converter 

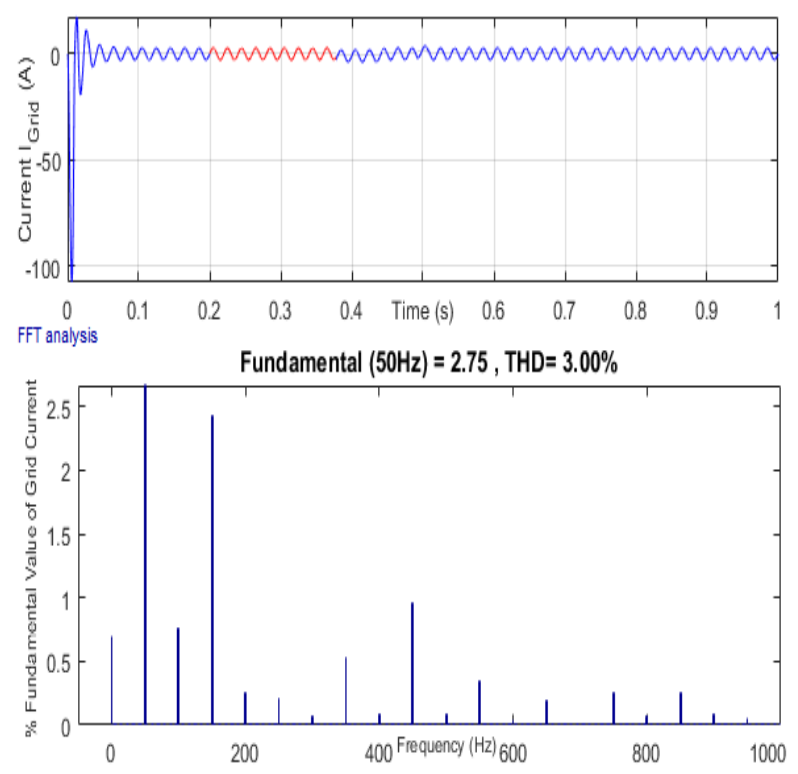

Fig.18. FFT evaluation of grid current using modified IC algorithm
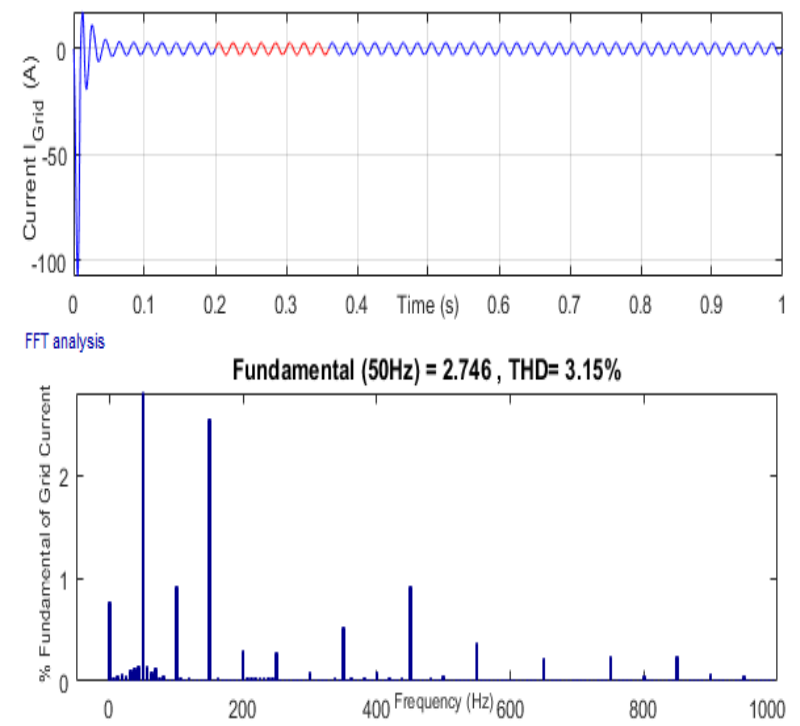

Fig.19. FFT evaluation of grid current using conventional IC algorithm

With 113.6V, Fig.13 shows the grid voltage after connected to d-q synchronous reference frame control. The proposed system is single phase hence generating zero steady state at grid frequency is a challenging task hence an orthogonal signal is generated and the generated alpha beta is shown in Fig.14.Voltage and current at output of grid should be in phase and is illustrated in Fig.15.The inverter and grid voltage is also synchronized and is shown in Fig.16.Thevoltage and current at the output of the boost converter is depicted in Fig.17.THD of the proposed model is reduced to 3\% shown in Fig. 18 and conventional model with $3.15 \%$ is shown in Fig. 19 states the proposed circuit is better than conventional system.

\section{V.CONCLUSION}

In this paper an extensive d-q Synchronous reference frame current control method for CHBMLI for single phase grid interfaced PV is analyzed and verified.The DC voltages of the inverter is replaced by means of solar PV system. A modified variable step size IC is adopted to track MPP andsame is analyzed with conventional IC algorithm. This improves the output power at the grid side. An LCL filter is used in order to suppress the lower frequency harmonics. A modified phase shifted is used for inverter switches. Phase locked loop is used for voltage and current grid synchronization. The proposed system is analyzed with different irradiance levels. Since no transformer is used the system is also cost effective. The overall efficiency of the system is about $98.7 \%$. THD of grid current is $3 \%$ and satisfies IEEE Standard value.

\section{REFERENCES}

1. Bose B K, "Global warming: Energy, environmental pollution, and the impact of power electronics,"IEEE Industrial Electronics Magazine, vol. 4, no. 1, 2010, pp.6-17.

2. J. M. Guerrero, F. Blaabjerget al"Distributed generation: Toward a new energy paradigm," IEEE Industrial Electronics Magazine, vol. 4, no. 1, 2010, pp.52-64.

3. Liserre. M,Sauter. T, and Hung J Y, "Future energy systems: Integrating renewable energy sources into the smart power grid through industrial electronics," IEEE industrial electronics magazine, vol. 4, no. 1, 2010, pp.18-37.

4. Esram. T, and Chapman P.I, "Comparison of photovoltaic array maximum power point tracking techniques,"IEEE Transactions on energy conversion, vol. 22, no. 2, 2007, pp.439-449.

5. M. A. G. De Brito et al,"Evaluation of the main MPPT techniques for photovoltaic applications,'IEEE transactions on industrial electronics, vol. 60, no. 3, 2013, pp.1156-1167.

6. Subudhi. B, and Pradhan. R, A comparative study on maximum power point tracking techniques for photovoltaic power systems. IEEE Transactions on sustainable energy, vol. 4, no.1, 2013, pp.89-98.

7. Sera. D,Mathe.L, Kerekes.T, Spataru S V, and Teodorescu. R,“On the perturb-and-observe and incremental conductance MPPT methods for PV systems,"IEEE journal of photovoltaics, vol. 3, no. 3, 2013, pp.1070-1078.

8. Elgendy M A, Zahawi B, and Atkinson D J, "Assessment of the incremental conductance maximum power point tracking algorithm," IEEE Trans. on Sustainable Energy, vol. 4, no. 1, pp. 108- 117, Jan. 2013.

9. K. Harini, and S. Syama, "Simulation and analysis of incremental conductance and Perturb and Observe MPPT with DC-DC converter topology for PV array." In Electrical, Computer and Communication Technologies (ICECCT),',IEEE International Conference on, 2015, pp. $1-5$.

10. V.S. Kirthika Devi, and Srivani S G,"Performance assessment of PV energy conversion system with Buck-Boost and Cuk converter for cascaded H-Bridge inverter. In Power and Energy Systems: Towards Sustainable Energy (PESTSE)," Biennial International Conference, 2016, pp. 1-6.

11. Liu F,Duan. S,Liu. F,Liu. B, and Kang. Y, "A variable step size INC MPPT method for PV systems," IEEE Trans. Industrial Electronics, vol.55, no.7, July 2008, pp. 2622-2628.

12. D. Menniti et al, "An incremental conductance method with variable step size for MPPT: Design and implementation," in Proc. Electrical Power Quality and Utilization Conf. (EPQU), Sept. 2009, pp.1-5.

13. N. E. Zakzouk et al, "Improved performance low-cost incremental conductance PV MPPT technique,'IET Renewable Power Generation, vol. 10, no. 4, 2016, pp.561-574.

14. Ned Mohan, and Tore. M,“Undeland. Power electronics: converters, applications, and design,”John Wiley \& Sons, 2007.

15. Umanand. L, "Power electronics essentials and applications." 1sted. New York, NY, Wiley Publishers, 2009.

16. Daniel Hart, “Power electronics,'Tata McGraw-Hill Education, 2011.

17. Rodriguez .J, Lai J S, and Peng F Z, "Multilevel inverters: a survey of topologies, controls and applications," IEEE Trans. Ind. Electron., vol. 49, no. 4, Aug. 2002, pp.724-738.

18. Rodríguez. J, Bernet S, Bin Wu, Pontt J O,Kouro S, "Multilevel voltage-source-converter topologies for industrial medium-voltage drives," IEEE Transactions on industrial electronics,vol. 54, no. 6 Dec-2007, pp. 2930-45. 
19. Malinowski. M, Gopakumar. K, Rodriguez. J,Perez M A, “A survey on cascaded multilevel inverters",IEEE Transactions on industrial electronics,vol. 57, no. 7, Jul 2010, pp. 2197-206.

20. G. Carrara et al,“A new multilevel PWM method: A theoretical analysis,'IEEE Transactions on power electronics, vol. 7, no. 3, July1992, pp. 497-505.

21. Franquelo L G, Rodriguez. J, Leon J L, Kouro S, Portillo. R, Prats M A, "The age of multilevel converters arrives,"IEEE industrial electronics magazine, vol. 2, no. 2, June 2008.

22. Bin Wu, and Mehdi Narimani,"High-power converters and AC drives,"John Wiley \& Sons, vol. 59, 2017.

23. V.S.Kirthika Devi and Srivani S G,"Modified phase shifted PWM for cascaded $\mathrm{H}$ bridge multilevel inverter",InAdvances in Electrical, Electronics, Information, Communication and Bio-Informatics (AEEICB), Third International Conference on,Feb 2017, pp. 89-94.

24. Hsieh G C, Hung J C, "Phase-Locked Loop Techniques A Survey,'IEEE Transactions on Industrial Electronics, vol. 43, No.6, December 1996, pp. 609-615.

25. Timbus. A, et al, "Evaluation of current controllers for distributed power generation systems," IEEE Trans. Power Electron., vol. 24, no. 3, Mar. 2009, pp. 654-664.

26. Castilla. M,Miret . J,Camacho A,Matas J,anddeVicuna L G, "Reduction of current harmonic distortion in three-phase grid-connected photovoltaicinvertersviaresonant currentcontrol," IEEE Trans. Ind. Electron., vol. 60, no. 4, Apr.2013, pp. 1464-1472.

27. Franceschini G, Lorenzani.E, Tassoni. C, and Bellini A, "Synchronous reference frame grid current control for single-phase photovoltaic converters," In Industry Applications Society Annual Meeting,IEEE, IAS'08, 2008, pp. 1-7.

28. Zhang. R, Cardinal. M, Szczesny. P, and Dame. M, "A grid simulator with control of single-phase power converters in DQ rotating frame," In Power Electronics Specialists Conference, 2002.(PESC).IEEE 33rd Annual, 2002, vol. 3, pp. 1431-1436.

29. Wen. B,Boroyevich. D, Burgos. R, Mattavelli. P, and Shen. Z "Analysis of DQ small-signal impedance of grid-tied inverters," IEEE Transactions on Power Electronics, vol. 31, no. 1, 2016, pp. 675-687.

30. Reznik. A, Godoy Simões M, A. Al-Durra, and Muyeen S. M, " LCL filter design and performance analysis for grid-interconnected systems," IEEE Transactions on Industry Applications, vol. 50, no. 2, 2014, pp. 1225-1232.

31. Ruan X, Wang X,Pan D, Yang D, Li W, and Bao C, "Design of LCL Filter." In Control Techniques for LCL-Type Grid-Connected Inverters,2018, pp. 31-61.

32. KangarluFarhadi, Mohammad, E. and F. Blaabjerg, "An LCL-filtered single-phase multilevel inverter for grid integration of PV systems," Journal of Operation and Automation in Power Engineering,vol. 4, no. 1, 2016,pp. 54-65.

33. Calais.M, Myrzik J.M.A, and Agelidis V G, "Inverters for single phase grid connected photovoltaic systems-Overview and prospects,' inProc. $17^{\text {th }}$ Eur. Photovoltaic Solar Energy Conf.,Munich,Germany, vol. 22-26,Oct. 2001, pp. 437-440.

34. González et al. "Transformerless inverter for single-phase photovoltaic systems," IEEE Transactions on Power Electronics,vol. 22, no. 2,2007, pp. 693-697.

35. González. R,Gubía E, López J, and Marroyo L, "Transformerless single-phase multilevel-based photovoltaic inverter," IEEE Transactions on Industrial Electronics,vol. 55, no. 7, 2008,pp. 26942702.

36. Teodorescu .R, Liserre . M and Rodrguez P, "Grid Converters for Photovoltaic and Wind Power Systems,’IEEE and John Wiley \& Sons, Ltd, 2011, ISBN: 978-0-470-05751-3

\section{AUTHORS PROFILE}

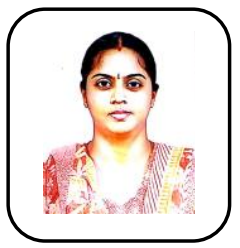

V. S. Kirthika Devi, Assistant Professor, Amrita School of Engineering, Bengaluru. She did her ME inAnna University and currently pursuing Ph.d under VTU in RV college of engineering. She has teaching experience of14 years. She has 7 International journal publications and 11International conferences. Her area of Interests areRenewable Energy Technology,Power electronics and control systems.

She is a membership of Technical Bodies inISTE.

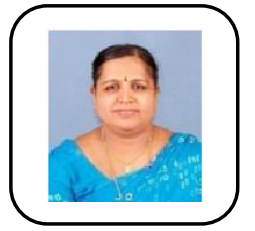

Dr. S. G. Srivani, Associate Professor\&Associate Dean in RV College of Engineering, Bengaluru. She did her ME in Bangalore University and $\mathrm{PhD}$ in NITK,Surathkal. She has teaching and research experience of about 31 years and industrial experience of 6 months. She has 42 International journal publications and 32 International/National conferences. Her area of Interests arePower System Protection and control, Smart grid and Renewable Energy Technology,Industrial Drives (ANN \& FL Applications). She is a membership of Technical Bodies as ISTE, IEEENo.90919504, IE and International Association of Engineers (IAENG).100259. She delivered many technical talks in international conferences and Chaired in many technical paper presentation sessions. She has been awarded for best paper 2017 in Inter-National Conferences at Imperial College, London. 